\title{
CAN NATIONAL ORAL HEALTH POLICY REFORM BE SUCCESSFULLY TRANSLATED INTO PRACTICE AND REDUCE THE BURDEN OF DISEASE IN AUSTRALIA?
}

\author{
Caitlyn Brennan', Md Shahidul Islam 2 \\ 1. Safer Care Victoria, VIC Australia \\ 2. School of Health, University of New England, NSW Australia
}

Correspondence: mislam27@une.edu.au

\section{ABSTRACT}

\section{BACKGROUND:}

The discrepancy between policy makers decisions, current research and clinical practice is of huge significance to the health industry and the Australian community.

AIM:

Evaluate of translational research frameworks and policy formulation within the Australian oral health context.

\section{METHODS:}

Following the Preferred Reporting Items for Systematic Reviews and Meta-Analyses (PRISMA) guidelines, a focused systematic search was conducted using an electronic search of the CINAHL database, including Medline, Cochrane and Scopus. A combination of key terms including "oral health", "prevention", 'translational research', "public policy", were used for the searches.

\section{RESULTS:}

The initial literature search found 561 abstracts in CINAHL database. Review against the inclusion criteria and removal of duplicates yielded 129 abstracts; further reviewed against the inclusion criteria resulted in 35 included in the review of translational research models. Across the 35 papers 8 different frameworks for translation of research evidence into policy and practice were utilised across the literature. The results reported in these studies show that the PARiHS framework depicts successful translation as a function of the relationship between evidence, context and facilitation. These interplays of elements are particularly of relevance to oral health due to the complexity of the sector. Context (current and historical) and facilitation (including governance/regulation) are the foundational drivers of successful implantation of evidence into practice.

\section{CONCLUSION:}

The PARiHS framework for implementing research into practice is an appropriate model for oral health. Universal access is a feasible step in addressing the current inequities of access to oral health care.

\section{KEYWORD}

oral health, policy reform, policy solutions, evaluation, practice, translational research, Australia. 
Many dental conditions are preventable and there are numerous evidence-based activities that are known to prevent oral disease and enable early detection and intervention. [1] Despite this available evidence the burden of oral disease within Australia is continually increasing. [2, 3] Since the introduction of the Australian Dental school scheme 1973 there have been several Commonwealth government initiatives that have been unsuccessful or abolished in addressing this issue. $[4,5]$

In Australia, the burden of oral disease is continually increasing. In 2011-12 the cost to the economy was \$8.3billion [2] and increased to \$9.9billion in 2015-16. [3] Oral health has historically been left out of overall health there is currently an increasing body of evidence linking the impact of poor oral health on whole body health, including mental health. [6] This siloing from the rest of health has resulted in additional complexity for policy solutions implementation and success.

Oral health has recently gained attention on the political agenda. In response to this attention high level policy makers and influencers are formulating policy solutions ideas including the proposed introduction of universal access to oral health care. [7] The discrepancy between policy maker's decisions, current research and clinical practice is of huge significance to the health industry and the Australian community. Within the Australian context lifestyle factors, low health literacy levels, socio-economic factors, access to services, inconsistencies in the implementation of public health initiatives are all identified as contributing factors to the current poor oral health status of Australians. $[3,5,6]$ There has been a historical marginalisation and siloing of dental health services and this has resulted in a primarily privatised sector and a disjointed emergency treatment focused public sector with extensive waitlists. [5]

The negative impact of poor oral health has on both the individual and the economy has also been extensively researched. Poor oral health is associated with lack of participation, reduced productivity, and avoidable hospital presentations. $[3,5,6$,$] At the individual level poor$ oral health can impact on an individual's ability to eat, speak and self-image. $[2,8]$ The body of evidence on the

implications of poor oral health and systemic health are extensive and continuing to grow with established likes between diabetes, cardiovascular disease, pneumonia and mental health. $[3,5,6]$

There has been a long-standing evidence base for oral health maintenance and disease prevention. At an individual level this involves simple, inexpensive oral hygiene activities such as tooth brushing and interdental cleaning, and dietary choices. [6,9] Water fluoridation has a long-standing evidence base of being a cost-effective public health initiative to reduce the prevalence and severity of oral disease. Within the clinical setting topical fluoride application and fissure sealants are also wellestablished preventive techniques. [8,9] The advances in dental research and treatment are such that we understand the disease process to enable early disease detection and interventions that arrest and reverse the disease process are highly successful. $[5,6]$

While we have seen many advances in the understanding and treatment of oral health and diseases, in Australia there has been little progress in a policy sense to translate this evidence successfully to reduce the burden of oral disease. [3,5] Oral health and public dental waiting lists have recently gained media attention [7] which has led to an increased amount of political attention and rise on the political policy agenda. [10] When national policy is successfully and appropriately translated into clinical practical practice not only does it result in efficient and effective use of public funds, it also leads to sustainable practices within the policy area. For example, the national immunisation strategy, since implementation in 1997 has been attributed the continued poliomyelitis (polio)-free status of Australia and to the successful elimination of endemic measles, in 2014 and rubella, in 2018. [11]

Despite the increased attention only a few studies have attempted to identify and synthesise evidence of the burden of oral disease within Australia. A preliminary search of literature showed that no systematic review has been conducted to appropriately translate high level policy into practical application. Therefore, the present study will be conducted to synthesize and critically appraise literature on the evaluation of translational research frameworks and policy formulation within the Australian oral health context. 
A mixed method approach was taken to evaluate the translational research frameworks and policy formulation within the Australian oral health context. Due to oral health policy being a complex area, expanding across both primary and public health systems as well as the limited availability of current peer reviewed literature within the Australian context. A systemic literature review was conducted, and the results of this review were then utilised as a part of the critically appraised topic. [12]

\section{RESEARCH PROTOCOL}

The PRISMA statement [13] was used as a framework for the literature component of the research.

\section{INFORMATION SOURCES}

A focused literature search was conducted using an electronic search of the CINAHL database, including Medline, Cochrane, and Scopus. Key words used included oral health, prevention, translational research, and public policy. Additional searches were conducted utilising recognised authority websites in this area including the Grattan Institute, professional dental bodies, State and Federal government agencies. Recent Australian media coverage on this topic was also reviewed to capture the current Australian context. Other sources used included identified studies after reviewing the reference list of identified articles.

\section{STUDY ELIGIBILITY CRITERIA}

Sources identified using the CINAHL database had to be from an academic peer reviewed journal and available in full text. Included studies were published in English between 2009 and 2018, and described frameworks, models or theories associated with research translation.
The initial literature search found 561 abstracts in CINAHL database. Review against the inclusion criteria and removal of duplicates yielded 129 abstracts; further reviewed against the inclusion criteria resulted in 35 included in the review of translational research models. Across the 33 papers 8 different frameworks for translation of research evidence into policy and practice were utilised across the literature.

FIGURE 1: THE PRISMA STATEMENT RESULTS

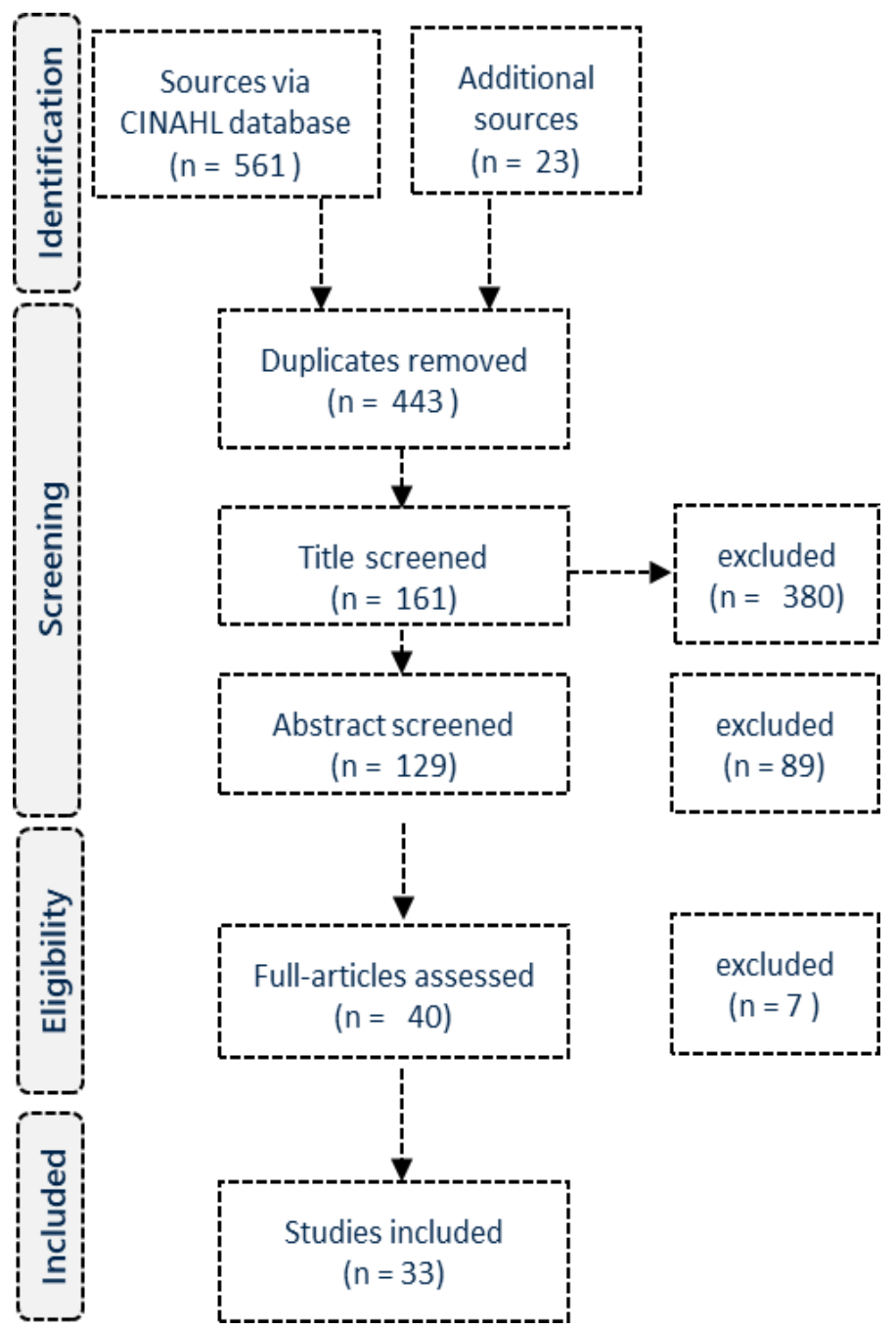




\section{STUDY OR ACADEMIC}

PAPER

Bakken and Ruland, 2009

[14]

Glasgow, Dickinson, Fisher, Christiansen, Toobert,

Bender, et al. 2011 [15]

Shubert, Altpeter and

Busby-Whitehead, 2011 [16]

Weiss, Jones, Lopez, VillarLoubet and Chitalu, 2011

[17]

Kim, Towers, Renaud, Zhou, Shea, Galvin and Volpp, 2012 [18]

Almeida, Pardo, Seidel, Davy, You, Wall, et al. 2014 [19]

Sweet, Ginis, Estabrooks and Latimer-Cheung, 2014 [20]

Matthews, Kirk, Macmillan and Mutrie, 2014 [21]

Altpeter, Gwyther, Kennedy, Patterson and Derence, 2015 [22]

\section{METHODOLOGY AND FINDINGS OVERVIEW}

Validation of RE-AIM across 2 case studies. Outcomes concluded the framework as valid in real world scenarios.

Use of RE-AIM to develop a multidimension health assessment tool that enables and guides patient-centred holistic interactions in management of common chronic illness seen in adult populations within the primary care setting.

Use RE-AIM framework to assess effectiveness of exercise-based research intervention within the community setting.

Results Partnerships between community and healthcare providers are key to successful implementation of falls prevention interventions.

Utilisation of "train the trainer" strategy, and the Glasgow RE-AIM models to guide and develop implementation strategies of research. Identifying stakeholder involvement and engagement (scientific, community, political) as key success factor.

Intervention reach and efficacy assessed individually and combined. Data collection via telephone interviews and focus groups.

Results: context and real-world constraints contribute to variance in impact across sites.

Development of a trial utilising the RE-AIM framework, in order to assess the effectiveness and cost of 3 different interventions.

RCT conducted with outcomes measures at baseline, 6, 12, and 18 months.

Use of each element of RE-AIM as a component of an operationalised framework for multi-sector partnerships.

Result has enabled the RE-AIM framework to be applicable to multi-sector partnerships to assess their public health impact.

A systematic review with the aim to report the findings of physical activity promotion interventions included during routine diabetes care utilising the RE-AIM framework for their process data.

Results were limited with inconsistencies with intervention duration and reporting data.

Use of RE-AIM framework to develop a multi-step mid-course assessment of the REACH II community translation project. Data collection involved quantitative (survey) and qualitative (discussion group) components. Results enablement of all stakeholders to have a voice via the assessment framework. 
STUDY OR ACADEMIC

PAPER

Khoury, Gwinn and loannidis, 2010 [23]

Glasgow, Vinson, Chambers, Khoury, Kaplan, Hunter and National, 2012 [24]

Drolet and Lorenzi, 2011 [25]

Callard, Rose and Wykes, 2012 [26]

Spoth, Rohrbach, Greenberg, Leaf, Brown, Faga, et al. 2013 [27]

Rubio, Robinson, Gilliam,

Primack, Switzer, Seltzer and Kapoor, 2014 [28]

Atchan, Davis and Foureu, 2014 [29]

\section{METHODOLOGY AND FINDINGS OVERVIEW}

Literature review into the applications of epidemiology into translational research via 4 phases (T1-T4). Finding there is an increased recognition of the role epidemiology plays in successful TR implementation and evaluation

To address the vast gap between current knowledge and practice in the area of dissemination and implementation research suggestion implementation of 5 core values: rigor and relevance, efficiency, collaboration, improved capacity, and cumulative knowledge is required

Literature review concluding whilst the 'translation continuum' is an appropriate description of translational research into practice, the current model is ineffective placing too much on translational research limiting the scope of the model and not accounting for all relevant factors.

Literature review on translational research and medicine the authors propose a linear model is not appropriate and an 'interlocking loop' is a model which service user and other stakeholder involvement feed into each of its elements.

Assessment of identified challenges to the furthering of T2 translational research "(1) building infrastructure and capacity to support systems-oriented scaling up of evidence-based interventions, with well-integrated practice-oriented T2 research, and (2) developing an agenda and improving research methods for advancing T2 translation science."

Concluding there is potential to enhance the health and well-being of future generations with refinement to the current $\mathrm{T} 2$ models used.

Interviews, assessing the usefulness of translational models. Concluding use of multiple models can assist with educators and mentors to guide investigators enabling increased productivity translational research.

Investigation to identify an appropriate theory and model to identify gaps and barriers between evidence and practice in the uptake of the BFHI in Australia.

Knowledge translation theory and the research to practice pipeline models most appropriate.

Concluding commonality of issues and barriers identified in this field in both the Australian and international context the knowledge translation theory and the research to practice pipeline model is of practical value to examine barriers. 
STUDY OR ACADEMIC

PAPER

Field, Booth, Ilott and Gerrish, 2014 [30]

Straus, Tetroe and Graham, 2011 [31]

Licskai, Sands, Ong, Paolatto and Nicoletti, 2012 [32]

Kastner and Straus, 2011 [33]

Sood, Manns and Nesrallah, 2014 [34]

\section{METHODOLOGY AND FINDINGS OVERVIEW}

Citation analysis and systematic review of studies applying the KTA framework to implementation projects finding the framework utilised across numerous settings and contexts with varying degrees of completeness. Concluding further research is required to explore and assess the true value of the KTA Framework.

Narrative review outlining what knowledge translation is and a framework for its use.

Finding key decision makers failing to use research evidence to support decision making is no uncommon there is numerous identified gaps within the literature including the need to develop valid strategies for assessing the determinants of knowledge use and for evaluating sustainability of knowledge translation interventions.

Utilisation of the KTA framework to develop an interdisciplinary asthma management program delivered across regional Canada at multiple sites.

Concluding the KTA framework was appropriate in guiding multi-level organizational change and delivers cost effective outcomes.

Descriptive analysis of applications of the KTA in conjunction with additional frameworks in the development of clinical tools. Concluding combined frameworks utilisation assists with addressing potential barriers and anticipating how knowledge will be sustained and disseminated.

Systematic review of the use of KTA to describe the planned Canadian knowledge translation strategy for improving knowledge and practices pertaining to the timing dialysis initiation.

Concluding use the KTA assists with identification of barriers and variation in practice.

TABLE 4: 2 OF THE INCLUDED PAPERS UTILISED THE PROMOTING ACTION ON RESEARCH IMPLEMENTATION IN HEALTH SERVICES (PARIHS) FRAMEWORK

\section{STUDY OR}

ACADEMIC PAPER

Stetler, Damschroder,

Helfrich and

Hagedorn, 2011 [35]

Bergström, Peterson,

Namusoko, Waiswa

and Wallin, 2012 [36]

\section{METHODOLOGY AND FINDINGS OVERVIEW}

Systematic review of PARIHS framework conclusion that the current model could be strengthened and developed a guide as a companion recommending both to be applied prospectively and comprehensively.

A qualitative study conducted in a district of Uganda, data collection via focus group discussions and semi-structured interviews utilising the PARIHS framework. Concluding "further development of the context assessment tool, assessing factors for successful implementation of evidence in low-income settings-resources, community involvement, and commitment and informal payment-should be considered for inclusion." 
STUDY OR ACADEMIC

PAPER

Jacobs, Jones, Gabella, Spring and Brownson, 2012 [37]

Hess, Eidson, Tlumak,

Raab and Luber, 2014 [38]

\section{METHODOLOGY AND FINDINGS OVERVIEW}

Review of EBPH models finding Key elements of EBPH are engaging the community in assessment and decision making; using data and information systems systematically; making decisions on the basis of the best available peer-reviewed evidence (both quantitative and qualitative); applying program-planning frameworks (often based in health-behavior theory); conducting sound evaluation; and disseminating what is learned.

Review of EBPH to develop an EBPH approach climate change concluding with modifications the EBPH is appropriate to, support climate change adaptation activities. There is however limited regarding successful interventions and knowledge translation, specifically in predicting future health impacts and outcomes.

\section{TABLE 6: 5 OF THE INCLUDED PAPERS UTILISED THE STAGES OF RESEARCH PROGRESSION (ROCKET MODEL)}

\section{STUDY OR ACADEMIC}

PAPER

Milat, Monger, Smith,

Bauman, Redman and

Goodger, 2011 [39]

Milat, Bauman, Redman and

Curac, 2011 [40]

Rissel, Laws, St George,

Hector, Milat and Baur, 2012

[41]

O'Hara, Phongsavan, King,

Develin, Milat, Eggins, et al. 2014 [42]

Rychetnik, Bauman, Laws, et al. 2012 [43]

\section{METHODOLOGY AND FINDINGS OVERVIEW}

Descriptive paper of the practical application of the "Nutbeam and Bauman Stages of Research and Evaluation Model" within the Australian context.

Systematic review of physical activity interventions in preventing falls finding limited intervention studies concluding moving towards replication and dissemination studies has a greater potential for improving population health.

Use of a scoring criterion applied within the five stages of an 'evidence-building' framework concluding the framework assisted in the identification of research and evaluation opportunities.

Evaluation of a population-based telephone service within the Australian context in order to identify improvement opportunities concluding "Translational formative evaluation is a necessary intermediate step, following efficacy studies and a precursor to population-wide implementation of public health programmes."

Review of the variations across the literature of the definition 'translation' within public health finding 4 district translational areas 


\section{STUDY}

Flaspohler, Lesesne, Puddy, Smith and Wandersman,

$2012[44]$

Chambers, 2012 [45]

\section{METHODOLOGY AND FINDINGS OVERVIEW}

A descriptive article on ISF evolution and current applications

A reflective article on the profession of ISF with discussion on the framework strengths and weaknesses

TABLE 8: 1 OF THE INCLUDED PAPERS REVIEWED THE UK MEDICAL RESEARCH COUNCIL (MRC) FRAMEWORK

STUDY

Barley, Haddad, Simmonds, Fortune, Walters, Murray, et al. 2012 [46]

\section{METHODOLOGY AND FINDINGS OVERVIEW}

Systemic review of the use of the Medical Research Council (MRC) guidelines for developing and evaluating complex interventions concluding that is an appropriate framework to use in the development of a depression and cardiac disease management program.

\section{TABLE 9: EVALUATION OF FRAMEWORKS}

\begin{tabular}{|c|c|c|}
\hline FRAMEWORK & KEY FINDINGS & $\begin{array}{l}\text { EVALUATION (WITHIN AUSTRALIAN ORAL } \\
\text { HEALTH CONTEXT) }\end{array}$ \\
\hline $\begin{array}{l}\text { RE-AIM } \\
\text { framework }\end{array}$ & $\begin{array}{l}\text { Framework may assist in policy comparisons } \\
\text { and impact estimations at a public health } \\
\text { level. Utilisation of the framework during } \\
\text { policy planning and development has been } \\
\text { attributed to success of policy } \\
\text { implementation and integration with other } \\
\text { existing strategies. }\end{array}$ & $\begin{array}{l}\text { Components of this model are particularly of } \\
\text { relevance with the successful integration of oral } \\
\text { health prevention strategies into general health } \\
\text { promotion. The highlighting of the maintenance of } \\
\text { implementation is specifically relevant in oral } \\
\text { health as has been attributed to previous policy } \\
\text { failings. }\end{array}$ \\
\hline $\begin{array}{l}\text { Translation } \\
\text { research } \\
\text { continuum or ' } \mathrm{T} \text { ' } \\
\text { models }\end{array}$ & $\begin{array}{l}\text { The model has evolved from a 2-step model } \\
\text { to a 5-step framework. Utilisation can assist in } \\
\text { identifying interventions that are likely to be } \\
\text { successful at a larger scale. }\end{array}$ & $\begin{array}{l}\text { This model has the strengths in enabling successful } \\
\text { scaling of interventions. The model is limited in its } \\
\text { approach to addressing all factors causing the } \\
\text { gaps between research translation into practice }\end{array}$ \\
\hline $\begin{array}{l}\text { The KTA } \\
\text { framework }\end{array}$ & $\begin{array}{l}\text { This conceptual framework can assist in } \\
\text { identification of barriers and variation in } \\
\text { practice across different contexts. }\end{array}$ & $\begin{array}{l}\text { Limitation in identifying the full extent of success } \\
\text { barriers and practice variations across the diversity } \\
\text { of settings within Australia. }\end{array}$ \\
\hline
\end{tabular}




\section{Promoting This frame work proposes that there is an Action on interplay between evidence \\ Research \\ Implementation \\ in Health \\ Services \\ (PARIHS) \\ framework \\ context/environment and method or way in \\ which the process is facilitated. With an \\ emphasis placed on context}

EBPH models

The stages of

research

progression

(rocket model)

The ISF

The MRC

framework
Provides the guidelines to develop clinical programs that account for multiple factors

and promote sustainability. areas and understand need and barriers. ISF proposes systems to bridge the gap between research and practice recognising implementation approaches utilising partnerships are preferable over top-down approach.
The strength of this framework is the identification of the key elements that are needed to be considered to determine success.

There is limited evidence of success outside of the organisational level.

This frame does however highlight key areas that have been identified as areas of failure in past oral health policies within Australia

The strength of this framework is the consideration to funding effectiveness and quality of evidenced used to formulate policy. The limitation is accounting for the historical complexities of oral health within Australia and the how this framework would translate across the private sector.

Utilisation of this model could be used throughout the evaluation development of future policies but has limited usability for oral health policy in the current Australian context, as there is already an extensive evidence base.

There is already an extensive body of research outlining need, priority and barriers to good oral health within Australia. This model could be utilised in future oral health policy development and assessments.

Not relevant in the Australian context

\section{DISCUSSION}

Currently in Australia there is jurisdictional variation in the eligibility, costs and type of oral health services provided by the public health sector, for example Victoria \& SA have a co-payment system, NSW \& QLD a free dental system. $[47,48,49,50]$ There are a number of national programs including the Child Dental Benefits Scheme [51] that can be utilised by eligible patients across both public and private dental providers. This is a relatively new initiative in comparison to other health initiatives provided by the government. $[4,5]$
Oral health has historically been separated from the remainder of the healthcare system both within Australia and internationally this is despite dentistry being one of the oldest medical professions, dating back to 7000 B.C. [52] Oral health has since significantly evolved in the way in which it is practiced, clinical staff are educated and the understanding of the important role oral health plays with an individual's systemic health.

Within Australia this evolution of the sector has resulted in a primarily privatised industry of tertiary trained clinicians, 
influential professional bodies, and a rapidly growing cosmetic component to oral health practices. The business models used in some of the sector has been subject to ethical practice questions and rorting of governmental payment systems contributing to policy failures. [5]

The identified skilled workforce shortage in 2010 led to the establishment of an additional three dental schools. The number of graduates has almost doubled, this influx of skilled workforce has not as intended filled the workforce gaps but instead contributed to the growth in the private practice component of the sector and significantly impacted on the culture of the sector.

FIGURE 2: THE SECTOR HAS DEVELOPED INTO A HIGHLY COMPLEX AREA WITH NUMEROUS FACTORS, STAKEHOLDERS AND CONTRIBUTORS THAT NEED TO BE CONSIDER IN DEVELOPMENT OF POLICY AND IMPLANTATION STRATEGIES

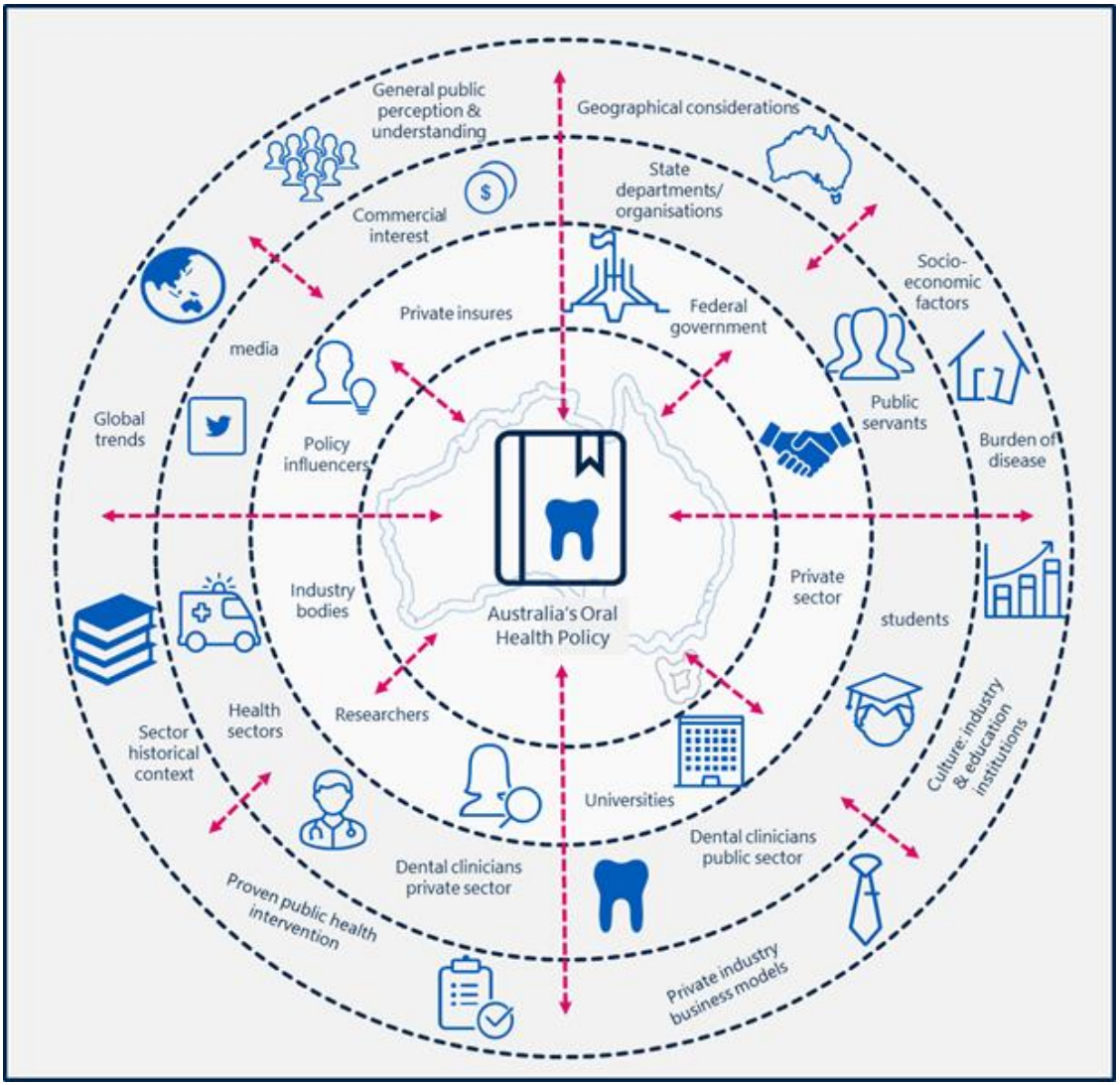

Generally, across the Australian healthcare system there is a continual generation of evidence for practice and patient outcome improvements. Closing the 'gap' between this current research and translating into policy and practice is an ongoing challenge. [43] Successful public policy implementations have a multi-platformed and staged approach including a change management strategy [53,54] and place-based policy. These strategies are of importance in the Australian context due to the variation in the population profiles and service availability across the jurisdictions. [54]

There are several models that have been developed in numerous fields that suggest pathways to address and close this gap between the research, policy, and practice. [53]

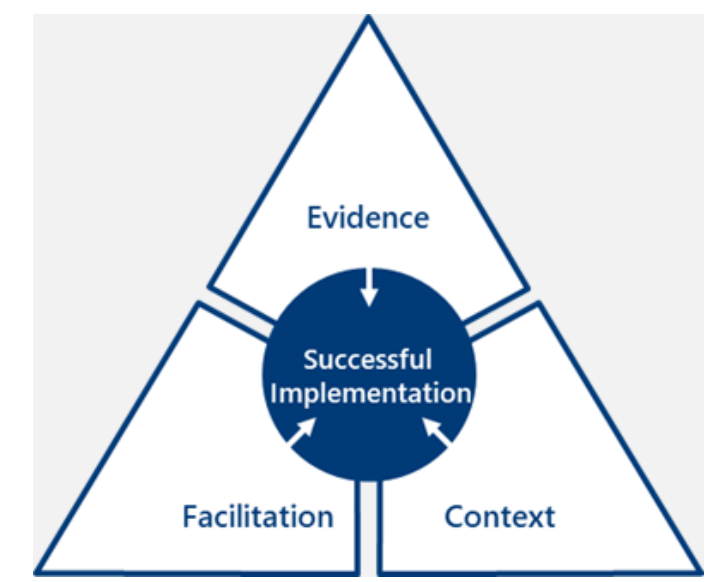

The PARiHS framework (Kitson, Harvey \& McCormack, 1998) [55] 
The PARiHS framework [53] depicts successful translation as a function of the relationship between evidence, context, and facilitation. These interplays of elements are particularly of relevance to oral health due to the complexity of the sector. Context (current and historical) and facilitation (including governance/regulation) are the foundational drivers of successful implantation of evidence into practice. These elements have both been identified as key factors to failings of previous policies.

RE-AIM framework has elements that can be utilised to compare and evaluate policy solutions. The highlighting of the maintenance phase of policy implementation is specifically relevant in oral health as has been attributed to previous policy failings.

[24] EBPH model elements can assist with development of policy solutions that deliver value for public funds and delivery of care in an equitable manner as it emphasises the use of high-quality evidence to support policy formulation. [38] The limitation of both the PARiHS and REAim frameworks have been validated at an organisational level rather than a national level. Within the literature there is limited evidence on frameworks that have been successfully utilised across different settings and jurisdictions and achieved long term sustainability and success.

In March 2019 the Grattan Institute published "Filling the gap: A universal dental scheme for Australia" [5] a report outlining the current shortcomings of the Australian oral health system and funding models, suggesting universal coverage scheme would improve the oral health of Australians through removal of current financial barriers in a number of jurisdictions and populations. There are several levers such as funding that can be used to drive change and reform in the sector. [5,56]. There are currently numerous royal commissions occurring across health system. [11] As this is the highest form of inquiry within Australia, they provide policy makers and regulators with the evidence and levers to enact systemic policy reform and increase governing and regulatory body powers. [57]

\section{CONCLUSIONS}

The current Australian context of previous policy failings and the recommendations of recent Royal Commissions indicate a need for stronger governance and a regulatory framework to strengthen the industry. There is an opportunity for significant policy reforms, tightened governance and increased regulatory capabilities in the current Australian context and policy makers should be emboldened by of the findings of recent of Royal Commissions.

Oral health education and prevention strategies needs to be integrated into general health initiatives and health practitioner training. Past government initiatives have not been developed in manner that adequately addresses the context, culture, and business models of the private sector. Components of the PARiHS framework for implementing research into practice is an appropriate model for oral health, in particular the emphasis on context considerations. Elements of the RE-AIM framework can be utilised to strengthen integration of oral health prevention strategies into general health promotion and maintenance of policy implementation. Successful and sustainable national policy implementation needs to include strong governance and regulatory frameworks to ensure compliance and to strengthen the industry.

\section{References}

1. Slayton RL, Urguhart $O$, Araujo MWB, Fontana M, Guzman-Armstrong S, Nascimento MM et al. Evidence-based clinical practice guideline on nonrestorative treatments for carious lesions: A report from the American Dental Association. The J Am Dent Assoc 2018; 149(10):837-849.

2. Australian Institute of Health \& Welfare (AIHW). Health expenditure Australia 2011 12: analysis by sector. Health and welfare expenditure series 51. Cat. no. HWE 60; 2014.

3. Manton D, Foley M, Gikas A, Ivanoski S, McCullough M, Peres Seselija A, et al. Australia's Oral Health Tracker: Technical Paper, Australian Health Policy Collaboration. Melbourne: Victorian University; 2018.

4. Akers HF, Weerakoon A, Foley M. McAuliffe A. J. The Medicare Chronic Disease Dental Scheme: Historical, Scientific, Socio-political Origins. J Hist Dent 2017; 65(2): 46-62.

5. Duckett S, Cowgill M, Swerissen H. Filling the gap: A universal dental scheme for Australia; 2019.

6. Australian Government (COAG). National Oral Health plan, health mouths health lives, Australia's National Oral Health Plan 2015-2024. Canberra: COAG; 2015.

7. Duckett S. The tooth hurts but Victoria's public dental system is broken. Melbourne: The Age; 2018. 
8. Choo A, Delac DM, Messer LB. Oral hygiene measures and promotion: Review and considerations. St.

Leonards: Aust Dent J 2001: 46(3).

9. Coxon A, Hayes DM, Wallace DJ. Perceived barriers to dietary advice provision by medical, dental and nursing personnel: a review of the literature. Int J Dent Hyg 2016; (2).

10. Walgrave S, Van Aelst P. The Contingency of the Mass Media's Political Agenda Setting Power: Toward a Preliminary Theory, Cary. J Commun. 2006; 56(1): 88109.

11. Australian Government (COAG). National Immunisation Strategy for Australia 2019 to 2024 Canberra: COAG, 2018.

12. Dawes M. Critically appraised topics and evidencebased medicine journals. Singapore Med J 2005; 46(9): 442

13. Moher D, Liberati A, Tetzlaff J, Altman DG. Preferred Reporting Items for Systematic Reviews and MetaAnalyses: The PRISMA Statement. PLOS Medicine 2009; 6(7).

14. Bakken S, Ruland CM. Translating clinical informatics interventions into routine clinical care: how can the RE-AIM framework help? J Am Med Inform Assoc. 2009;16(6):889-97.

15. Glasgow RE, Dickinson $P$, Fisher $L$, Christiansen $S$, Toobert DJ, Bender BG, et al. Use of RE-AIM to develop a multi-media facilitation tool for the patientcentered medical home. Implement Sci. 2011;6:118.

16. Shubert TE, Altpeter M, Busby-Whitehead J. Using the RE-AIM framework to translate a research-based falls prevention intervention into a community-based program: lessons learned. J Safety Res. 2011;42(6):50916.

17. Weiss SM, Jones DL, Lopez M, Villar-Loubet O, Chitalu N. (2011) The many faces of translational research: a tale of two studies. Transl Behav Med. 201 1;1 (2):32730 .

18. Kim AE, Towers A, Renaud J, Zhou J, Shea JA, Galvin R, Volpp KG. Application of the RE-AIM framework to evaluate the impact of a worksite-based financial incentive intervention for smoking cessation. J Occup Environ Med. 2012;54(5):610-14.

19. Almeida FA, Pardo KA, Seidel RW, Davy BM, You W, Wall SS, et al. Design and methods of "diaBEAT-it!": a hybrid preference/randomized control trial design using the RE-AIM framework. Contemp Clin Trials 2014; $38(2): 383-96$.

20. Sweet SN, Ginis KAM, Estabrooks PA, Latimer-Cheung AE. Operationalizing the RE-AIM framework to evaluate the impact of multi-sector partnerships. Implement Sci. 2014;9 (74).

21. Matthews L, Kirk A, Macmillan F, Mutrie N. Can physical activity interventions for adults with type 2 diabetes be translated into practice settings? A systematic review using the RE-AIM framework. Transl Behav Med. 2014;4(1):60-78.

22. Altpeter M, Gwyther LP, Kennedy SR, Patterson TR, Derence K. From evidence to practice: using the REAIM framework to adapt the REACHII caregiver intervention to the community. Dementia (London). 2015;14(1):104-13.

23. Khoury MJ, Gwinn M, loannidis JPA. The emergence of translational epidemiology: from scientific discovery to population health impact. Am J Epidemiol. 2010;172(5):517-24.

24. Glasgow RE, Vinson C, Chambers D, Khoury MJ, Kaplan RM, Hunter C. National Institutes of Health approaches to dissemination and implementation science: current and future directions. Am J Public Health. 2012;102(7):1274-81.

25. Drolet BC, Lorenzi NM. Translational research: understanding the continuum from bench to bedside. Transl Res. $2011 ; 157(1): 1-5$.

26. Callard F, Rose D, Wykes T. Close to the bench as well as at the bedside: involving service users in all phases of translational research. Health Expect. 2012;15(4):389-400.

27. Spoth R, Rohrbach LA, Greenberg $M$, Leaf $P$, Brown $\mathrm{CH}$, Faga A, et al. Addressing core challenges for the next generation of type 2 translation research and systems: the translation science to population impact (TSci Impact) framework. Prev Sci. 2013;14(4):319-51.

28. Rubio DM, Robinson GF, Gilliam VA, Primack BA, Switzer GE, Seltzer DL, Kapoor WN. Characterization of investigators' approach to translational research: a qualitative study. Clin Transl Sci. 2014;7(6):441-6.

29. Atchan M, Davis D, Foureur M. Applying a knowledge translation model to the uptake of the Baby Friendly Health Initiative in the Australian health care system. Women Birth. 2014;27(2):79-85. 
30. Field B, Booth A, llott I, Gerrish K. Using the Knowledge to Action Framework in practice: a citation analysis and systematic review. Implement Sci. 2014;9:172.

31. Straus SE, Tetroe JM, Graham ID. Knowledge translation is the use of knowledge in health care decision making. J Clin Epidemiol. 2011;64(1):6-10.

32. Licskai C, Sands T, Ong M, Paolatto L, Nicoletti I. Using a knowledge translation framework to implement asthma clinical practice guidelines in primary care. Int J Qual Health Care. 2012;24(5):538-46.

33. Kastner M, Straus SE. Application of the Knowledge-toAction and Medical Research Council frameworks in the development of an osteoporosis clinical decision support tool. J Clin Epidemiol. 2012;65(11):1163-70.

34. Sood MM, Manns B, Nesrallah G. Using the knowledge-to-action framework to guide the timing of dialysis initiation. Curr Opin Nephrol Hypertens. 2014;23(3):321-7.

35. Stetler CB, Damschroder LJ, Helfrich CD, Hagedorn HJ. A guide for applying a revised version of the PARIHS framework for implementation. Implement Sci. $2011 ; 6: 99$.

36. Bergström A, Peterson S, Namusoko S, Waiswa P, Wallin L. Knowledge translation in Uganda: a qualitative study of Ugandan midwives' and managers' perceived relevance of the sub-elements of the context cornerstone in the PARIHS framework. Implement Sci. 2012; 7:117.

37. Jacobs JA, Jones E, Gabella BA, Spring B, Brownson RC. Tools for implementing an evidence-based approach in public health practice. Prev Chronic Dis. 2012;9:E116

38. Hess JJ, Eidson M, Tlumak JE, Raab KK, Luber G. An evidence-based public health approach to climate change adaptation. Environ Health Perspect. 2014;122(11):1177-86.

39. Milat AJ, Monger C, Smith J, Bauman A, Redman S, Goodger B. The strategic development of the NSW health plan for prevention of falls and harm from falls among older people: 2011-2015; translating research into policy and practice. N S W Public Health Bull. $2011 ; 22(3-4): 73-7$.

40. Milat AJ, Bauman AE, Redman S, Curac N. Public health research outputs from efficacy to dissemination: a bibliometric analysis. BMC Public Health. 2011;11:934.
41. Rissel C, Laws R, St George A, Hector D, Milat AJ, Baur LA. Research to practice: application of an evidencebuilding framework to a childhood obesity prevention initiative in New South Wales. Health Promot J Austr. 2012;23(1):16-24.

42. O'Hara BJ, Phongsavan P, King L, Develin E, Milat AJ, Eggins D, et al. 'Translational formative evaluation': critical in up-scaling public health programmes. Health Promot Int. 2014;29(1):38-46.

43. Rychetnik L, Bauman A, Laws R, King L, Rissel C., Nutbeam D, et al. Translating research for evidencebased public health: key concepts and future directions. J Epidemiol Community Health. 2012;66(12):1 187-92.

44. Flaspohler P, Lesesne CA, Puddy RW, Smith E, Wandersman A. Advances in bridging research and practice: introduction to the second special issue on the interactive system framework for dissemination and implementation. Am J Community Psychol. 2012;50(3-4):271-81.

45. Chambers DA. The interactive systems framework for dissemination and implementation: enhancing the opportunity for implementation science. Am J Community Psychol. 2012;50(3-4):282-4.

46. Barley EA, Haddad M, Simmonds R, Fortune Z, Walters P, Murray J, et al. The UPBEAT depression and coronary heart disease programme: using the UK Medical Research Council framework to design a nurse-led complex intervention for use in primary care. BMC Fam Pract. 2012;13:119.

47. Dental health Services Victoria (DHSV). Dental services. 2018. Available at :https://www.dhsv.org.au/public-dentalservices/dental-services-available

48. South Australia Health (SA Health). SA Dental Service. 2019. Available at:

https://www.sahealth.sa.gov.au/wps/wcm/connect/ public+content/sa+health+internet/health+services/d ental+services/sa+dental+service/frequently+asked+q vestions+about+dental+services\#A19Whatiflcantaffor dthefees?

49. New South Wales Health (NSW Health) (2017) Eligibility of persons for Public Oral Health Care in NSW. 2017. Available at: https://www1.health.nsw.gov.au/pds/ActivePDSDocu ments/PD2017_027.pdf 
50. Queensland Health (QLD Health) Public Oral Health Services. 2019. Available at:

https://www.health.qld.gov.au/oralhealth/services/sc hool

51. The Department of Health (Dept. Health). The Child Dental Benefits Schedule. 2018. Available at:

https://www.health.gov.au/internet/main/publishing.n sf/content/childdental

52. American Dental Education Association (ADEA). History of Dentistry. 2015. Available at: https://www.adea.org/GoDental/Health_Professions Advisors/History_of_Dentistry.aspx

53. Andrew J, Milata B, Ben L. Narrative review of frameworks for translating research evidence into policy and practice Canberra: Public health research \& practice, 2017 15;27(1).

54. Dankwa-Mullan I, Pérez-Stable E. Addressing Health Disparities Is a Place-Based Issue. Am J Public Health. 2016;106 (4):637-639.

55. Kitson A, Harvey G, McCormack B. Enabling the implementation of evidence-based practice: a conceptual framework. Qual Health Care. 1998; 7:149-158.

56. Deerberg-Wittram J, Guth C, Porter M. Value-based Competition: the Role of Outcome Measurement, Germany. Public Health Forum. 2013; 21 (4):12.e112.e3.

57. Australian Law Reform Commission (ALRC). 2010. Available at: https://www.alrc.gov.au/inquiries/royalcommissions-and-official-inquiries. 